\title{
Insights into the Mechanisms of Screw Feeder Plugging by Heated Pine Forestry Residues Using In-situ and Correlative Microscopy
}

\author{
Josephine Gruber, Yining Zeng, Steven Rowland, Daniel Carpenter and Bryon Donohoe
}

National Renewable Energy Laboratory, Golden, Colorado, United States

Increasing concerns about global carbon emissions due to fossil fuel use has created interest in renewable fuel alternatives, such as lignocellulosic biomass. With an estimated global biomass production probability ten-fold higher than projected need, functionalizing and scaling biomass conversion processes, like pyrolysis, is a promising component of a diverse sustainable energy program (Kan, Strezov, \& Evans, 2016). Pyrolysis reactors employed in biomass conversion often encounter the known problem of screw feeder plugging, halting work and reducing efficiency of biorefineries. Although the screw feeder is not heated directly, conductive heat transfer from the fluidized bed pyrolysis reactor creates a temperature gradient, where particles experience temperatures between $22^{\circ} \mathrm{C}$ and $500^{\circ} \mathrm{C}$ from the time they enter the feeder to being emptied into the reactor (Digman, Joo, \& Kim, 2009; Nieminen \& Folke, 1982). The impact of unintentional heating on this highly variable feedstock may result in particle morphology modification, surface texture transformation, and the evolution of viscous compounds and may contribute to screw feeder plugging (Haas, Nimlos, \& Donohoe, 2009; Ingram et al., 2008). We hypothesized that particles of various anatomical fractions (including needles, branches, bark, cambium, and whitewood) will experience dramatic changes during this heating regime, which will be characterized by decreased particle size, increased surface roughness, degradation of key structural macromolecules, and generation of viscous compounds that would result in increased particle friction and cohesion, contributing to screw feeder plugging.

To determine the effects of heating during screw feeder conveyance on variable pine forestry residue feedstocks, we used in situ hot stage microscopy, scanning electron microscopy (SEM), and stimulated Raman spectroscopy (SRS) to isolate critical temperatures related to changes in particle morphology and surface chemistry that may contribute to screw feeder plugging. Optical in situ microscopy experimentation on different pine anatomical fractions indicates that particles compress at a maximal rate near $375^{\circ} \mathrm{C}$ (Figure 1). Heated particles were then quenched and retained for correlative analysis by SRS and SEM microscopy. The Raman spectra identify changes in surface chemistries that may contribute to screw feeder plugging and identify the volatile liquid compounds emerging from biomass during in situ experimentation. Correlative analysis using SEM facilitated analysis and quantification of particle surface texture and cell wall morphology (Figure 2). We predicted that the gradual heating that particles experience during screw feeder conveyance would increase surface roughness and partially degrade some major structural macromolecules resulting in premature production of bio-oil. We further predict that the increased friction created by rougher particles and the viscosity of bio-oils will increase interaction among particles and between particles and the screw feeder surface resulting in screw feeder plugging that could halt pyrolysis reactor processes. Using in situ and correlative microscopy techniques, we have characterized the effects of variable heating on pine anatomical fractions that will inform engineering solutions to prevent screw feeder malfunctions and optimize pyrolysis performance. 

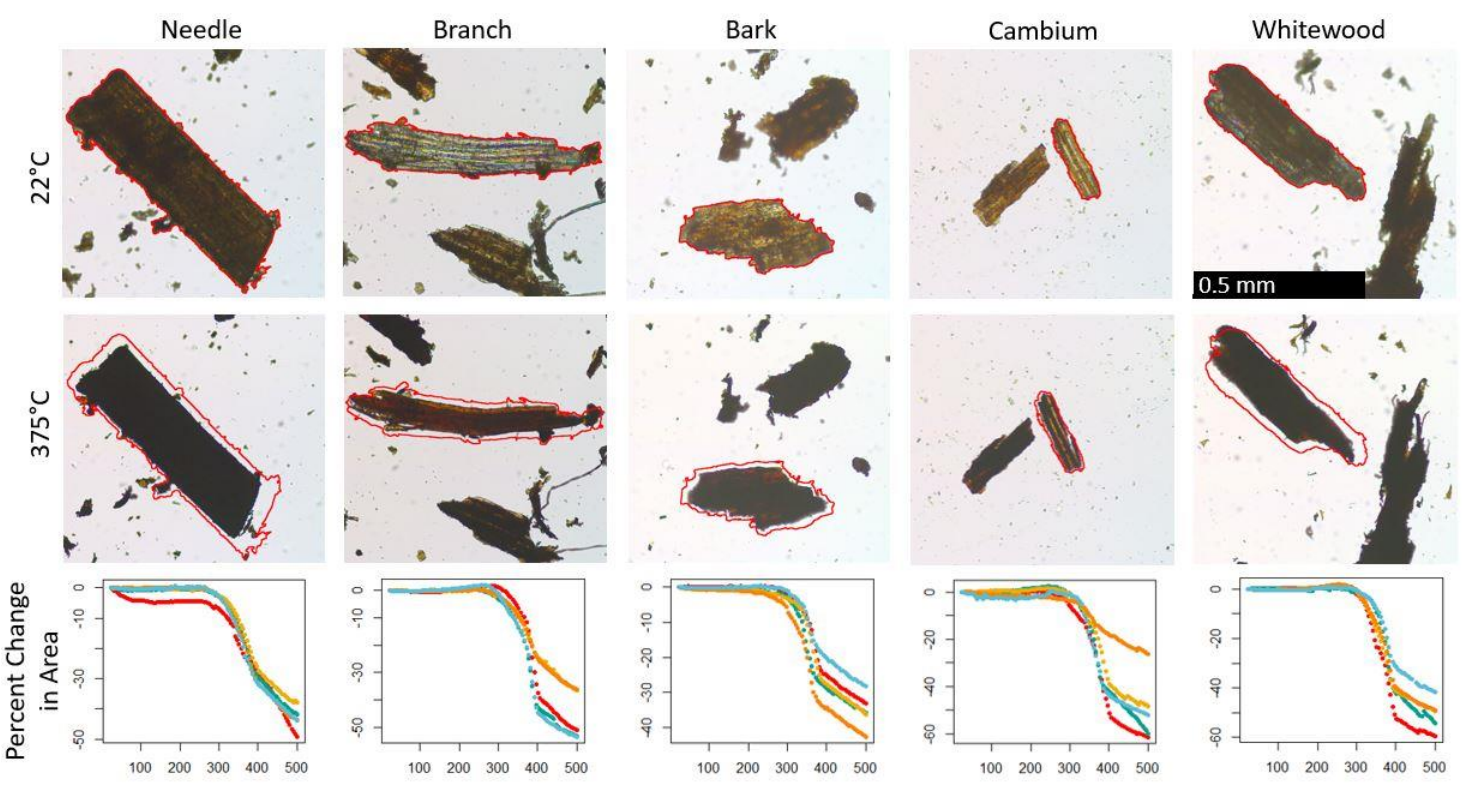

Temperature $\left({ }^{\circ} \mathrm{C}\right)$

Figure 1. Selected frames of time-lapse movies collected over 96 minutes of in situ particle heating from $22^{\circ} \mathrm{C}$ to $500^{\circ} \mathrm{C}$ at a rate of $5^{\circ} \mathrm{C} /$ minute for each anatomical fraction investigated (needle, branch, bark, cambium, and whitewood). Red outlines indicate initial particle size and general morphology before heating. Frames taken as particles reached $375^{\circ} \mathrm{C}$ are characteristic of maximal shrinkage observed between approximately $325^{\circ} \mathrm{C}$ and $400^{\circ} \mathrm{C}$. Time-lapse movies were analyzed frame by frame to quantify relative particle size fluctuations during heating and were used to identify areas of major morphological change to be investigated further by SEM and SRS. Indicated scale applicable to all micrographs.
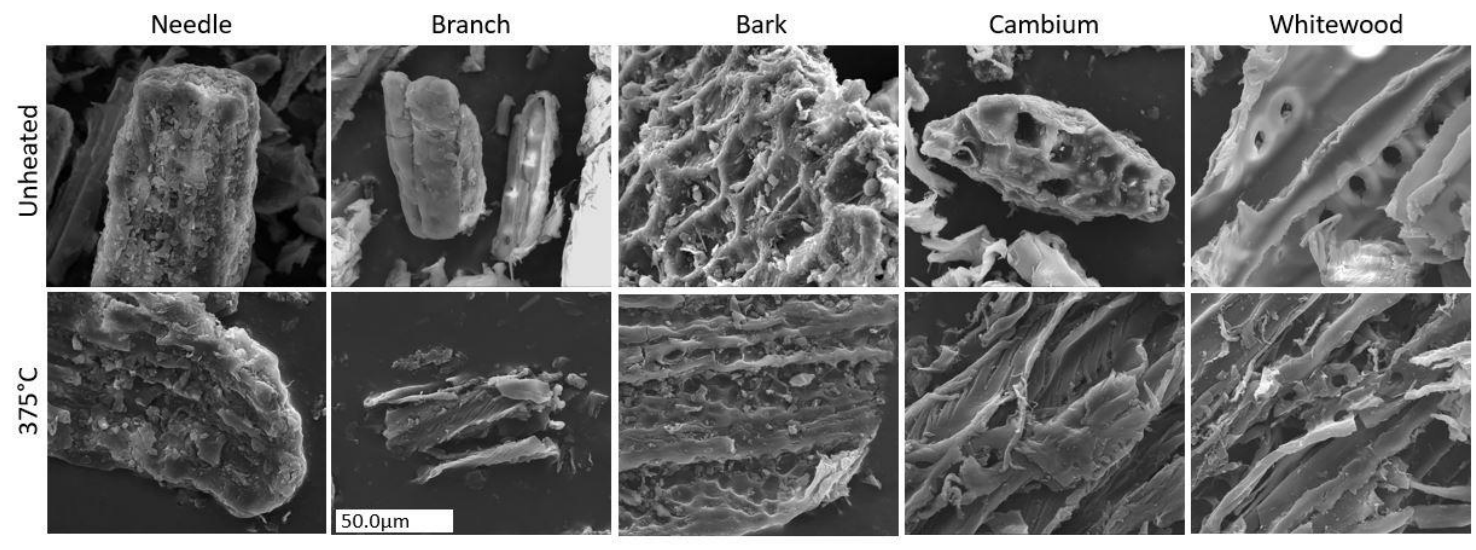

Figure 2. SEM micrographs of five anatomical fractions (needle, branch, bark, cambium, and whitewood) found in pine forestry residue material used in pyrolysis. Particle morphology and surface texture was compared between unheated particles and particles heated $375^{\circ} \mathrm{C}$. Particles heated to $375^{\circ} \mathrm{C}$ show noticeable changes in overall morphology and an increase in surface roughness. Degradation and delamination of the cell wall are also evident. 


\section{References}

Digman, B., Joo, H. S., \& Kim, D. S. (2009). Recent progress in gasification/pyrolysis technologies for biomass conversion to energy. Environmental Progress \& Sustainable Energy: An Official Publication of the American Institute of Chemical Engineers, 28(1), 47-51.

Haas, T. J., Nimlos, M. R., \& Donohoe, B. S. (2009). Real-time and post-reaction microscopic structural analysis of biomass undergoing pyrolysis. Energy \& fuels, 23(7), 3810-3817.

Ingram, L., Mohan, D., Bricka, M., Steele, P., Strobel, D., Crocker, D., ... \& Pittman Jr, C. U. (2008). Pyrolysis of wood and bark in an auger reactor: physical properties and chemical analysis of the produced bio-oils. Energy \& Fuels, 22(1), 614-625.

Kan, T., Strezov, V., \& Evans, T. J. (2016). Lignocellulosic biomass pyrolysis: A review of product properties and effects of pyrolysis parameters. Renewable and Sustainable Energy Reviews, 57, 11261140.

Nieminen, J. J., \& Folke, E. (1982). U.S. Patent No. 4,311,670. Washington, DC: U.S. Patent and Trademark Office. 